\title{
Analysis of Thermal Energy Distribution from Low Yield Nuclear Explosions
}

\author{
Jinan Abdil-Hasan ${ }^{1}$ \\ ${ }^{1}$ AlMustansiriya University, Iraq \\ Correspondence: Jinan Abdil-Hasan, AlMustansiriya University, Iraq. E-mail: Jinansna@yahoo.com
}

Received: May 18, 2017

Accepted: May 25, 2017

Online Published: June 27, 2017

doi:10.5539/mas.v11n8p1

URL: https://doi.org/10.5539/mas.v11n8p1

\begin{abstract}
This study is dedicated for the determination of the distribution of thermal energy resulted from different types of a 50-70 KT yield nuclear explosion; surface, aerial, in different locations away from the explosion center and considering the differences in the transmittance factor and visibility conditions that may affect the distribution of thermal energy. The results showed that the majority of released thermal energy occurs during a very short period of time after explosion, and reaches its maximum of $22 \mathrm{KT}$ after about $3.1 \mathrm{sec}$. Also, it was determined the absence of significant effect for the visibility degree on the value of the total thermal exposure for both types of explosions, and that the thermal exposure due to the surface explosion is about $60 \%$ of its value in case of the aerial explosion.
\end{abstract}

Keywords: nuclear explosion, thermal energy, surface explosion, aerial explosion, visibility

\section{Introduction}

The thermal energy represents one of the major hazards due to nuclear explosions with its drastic impacts either for humans or other species and materials consequences vary from eyes and skin burns to the ignition of combustible materials like buildings, woods, fabrics, etc., that is in addition to the rapid high temperature rise that follows its absorbance by the surrounding environment. Hence, the goal of this study is to estimate the pattern and amount of thermal energy that would be released by low yield nuclear explosions, especially that thermal energy represents about one third of nuclear explosion's yield. Such target involves the serious consideration for the prevailing conditions that may affect the thermal energy distribution away from the point zero, such as the explosion type (surface, aerial, or subsurface), wind speed, visibility and transmittance. Due to the huge danger and problematic complexes involved with such kind of studies in addition to the great cost, the whole analysis will be based on the most well-known simulation formulas for the release of thermal energy from a nuclear explosion.

\section{Theoretical Basis}

With the Black body assumption for the fire ball as a result of a nuclear explosion, the energy distribution of various temperature ranges might be approached by Plank`s formula (Kramm and Mölders, 2009):

$$
E=\frac{8 \pi h c}{\lambda^{5}} \cdot \frac{1}{e^{h_{c / \lambda} K T}}
$$

Where:

h: Plank`s constant, $6,636 \times 10^{34} \mathrm{~J} . \mathrm{sec}$; $h_{c / \lambda}$ : energy of photon with.$\lambda$ wave length. K: Boltzmann's constant, $1.38 \times 10^{-23} \mathrm{~J} / \mathrm{K}$; c: speed of light, m/sec.; T: Absolute temperature, $\mathrm{K}$.

The energy emission rate at a certain wave length would be calculated as:

$$
\mathrm{J}_{\lambda}=\frac{c}{4} E_{\lambda}
$$


As short waved radiations like the ultraviolet radiation are absorbed through the space between the explosion point and the ground, the thermal energy that reaches the ground with long wave lengths is significantly less than that originated from the fire ball (Wm. Robert Johnston, 2008). Accordingly, the total thermal energy emission rate $(\mathrm{P})$ from an explosion energy $(\mathrm{w})$ is determined as:

$$
P=4 \pi \sigma T^{4} R^{2}
$$

where: $\sigma$ : Stephan Boltzmann constant, $5.67 \times 10^{-8} \mathrm{~J} / \mathrm{K} . \mathrm{sec} . \mathrm{m}^{2}$

The thermal energy emission rate and the emitted thermal energy due to an explosion of a certain yield; $\mathrm{w}$ can be determined from figure 1, while maximum thermal energy that can be reached at a time; $t_{\max }$ after the detonation equals:

$$
t \max \approx 0.0517 w^{0.44}
$$

and;

$$
\mathrm{P}_{\max }=3.18 \mathrm{w}^{0.56}
$$

Where: $\mathrm{w}$ is the explosion energy, KT

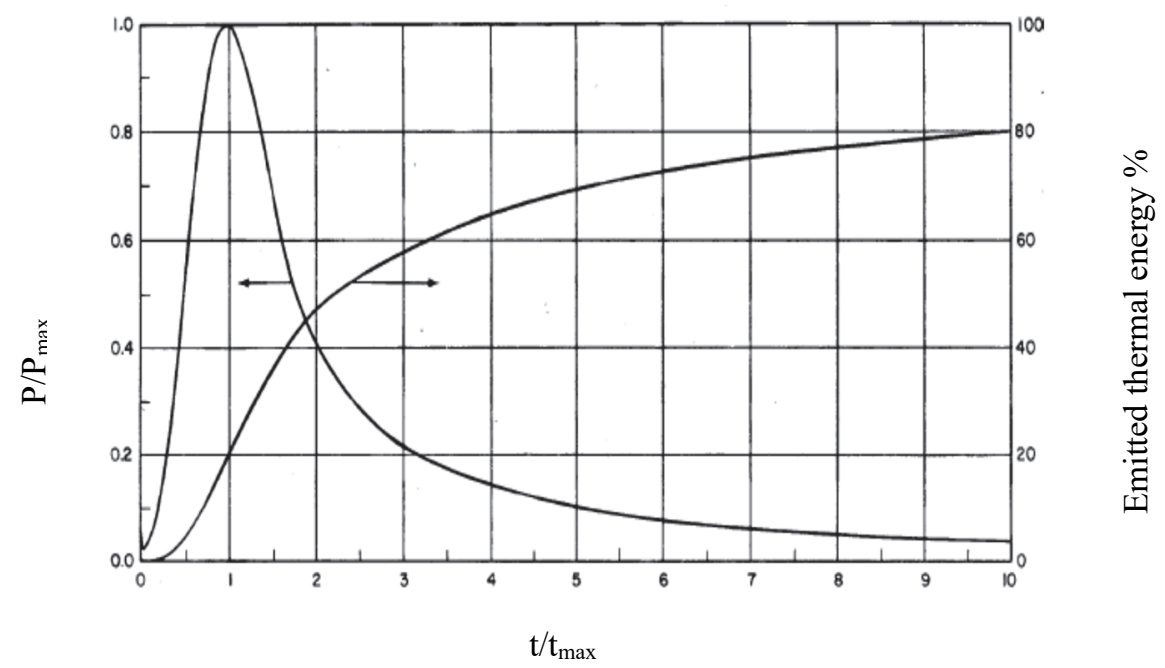

Figure 1. Thermal energy analysis vs. time for aerial nuclear explosions (Glasstone and Dolan, 1977)

Taking into consideration that all above calculation are valid for explosions that occur at elevations below $5 \mathrm{Km}$ from the ground where air has sensible density (Glasstone, 2012; DeVolpi et.al, 2004). Also, the thermal exposure (Q) as a result of an aerial nuclear explosion, taking the scattering and absorption through air may be calculated as follows:

$$
Q=\frac{E_{t o t} \Gamma}{4 \pi D^{2}}
$$

Where:

$\mathrm{E}_{\mathrm{to}} \mathrm{t}$ : total thermal energy; D: Distance from point zero, $\mathrm{m}$.

The transmissivity $\Gamma$ is related to the solid angle between the scattered radiation and its target as shown in figure 2, and the total emitted thermal energy $E_{\text {tot }}$ equals:

$$
E_{\text {tot }}=\mathrm{w} f
$$

the value of $f$ is in the range $0.3-0.35$ for explosion energies 10-100 KT, respectively, hence the thermal exposure due to an aerial nuclear explosion may be determined as follows: 


$$
Q=\frac{f w \Gamma}{4 \pi D^{2}}
$$

The thermal exposure due to surface explosion would be less than that due to an aerial explosion of the same energy. That is attributed to the reduction in transmissivity at lower air layers due to the presence of dust and water vapor that is resulted from the explosion, which makes the thermal exposure due to surface explosion about $0.5-0.75$ of that due to an aerial explosion, depending on the explosion energy, meteorological factors and distance from the explosion center as follows (Lamarsh and Baratta, 2017):

$$
Q \approx 0.75 \text { to } 0.5 \frac{f w \Gamma}{4 \pi D^{2}}
$$

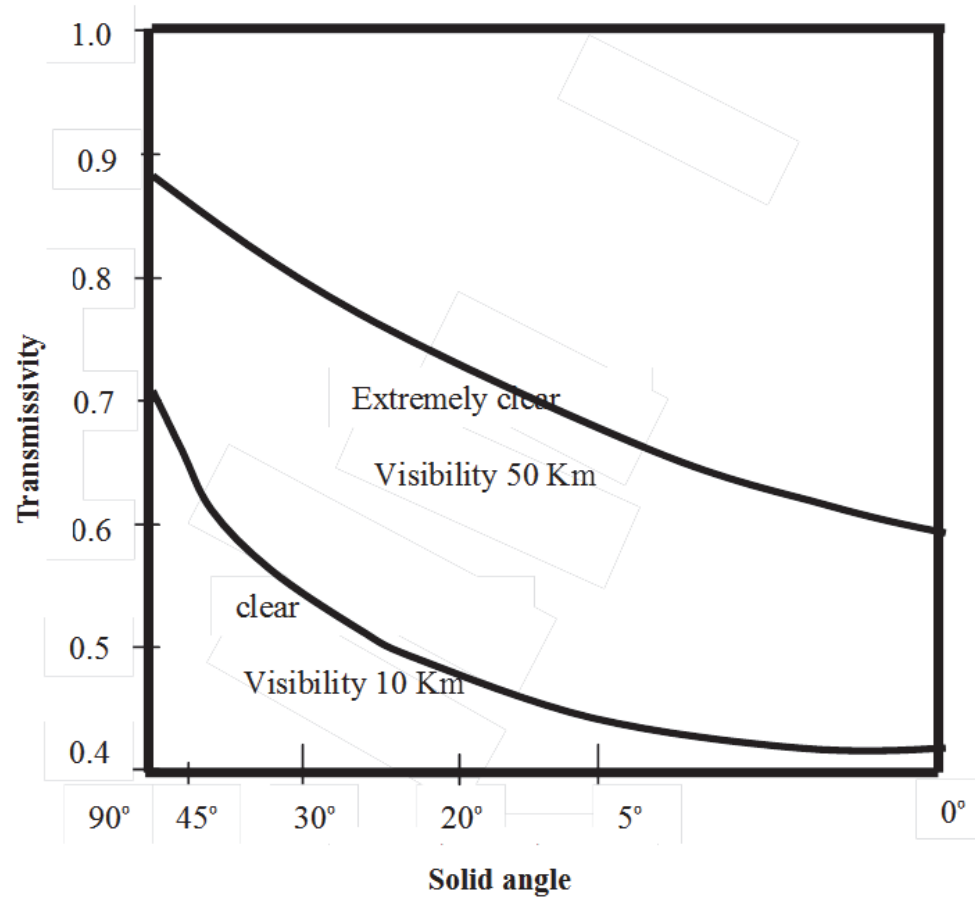

Figure 2. Transmissivity as a function of distance from the explosion location for two visibility degrees

(ANL-5800)

\section{Results and Discussions}

The thermal yield due to nuclear explosions 50-70 KT, and its distribution over the area around the point zero are determined benefiting from equations 8 and 9 in addition to figure 2, for aerial and surface explosions. In general, the total energy yield is gradually increased with time after the explosion to reach its highest record of about 20-23 KT in about $3.1 \mathrm{sec}$. (figure 4). In consequence, figure 3 demonstrates that the thermal energy emission rate rapidly increases to reach its peak of $31.49 \mathrm{Kcal} / \mathrm{sec}$, in about $0.313 \mathrm{sec}$, , after the explosion, then rapidly decreases to its $40 \%$ of that value about $0.35 \mathrm{sec}$. later, after which gradually decreases to about $5 \%$ of its peak in about $1.14 \mathrm{sec}$.

For both types of explosions, the thermal exposure acutely decreases away from the point zero and for both visibility levels of $10 \mathrm{Km}$ and $50 \mathrm{Km}$, as it is demonstrated by figure 5 . In comparison with its record at $0.16 \mathrm{Km}$ from point zero where it is about $6000 \mathrm{cal} / \mathrm{cm}^{2}$, for an aerial explosion, the thermal exposure reaches around $25 \%$ of that record at $0.32 \mathrm{Km}$ away from that location, and keeps decreasing, although moderately until it becomes about $1 \%$ of that record at $1.45 \mathrm{Km}$ (figure $5 \mathrm{a}$ ). in a similar manner, the thermal exposure due to a surface explosion reaches $25 \%$ of its initial value of about $4630 \mathrm{cal} / \mathrm{cm}^{2}$ at around $0.4 \mathrm{Km}$ distance from point zero and keeps decreasing to reach its $1 \%$ of that value at about $2 \mathrm{Km}$ distance as shown in figure $5 \mathrm{~b}$. 


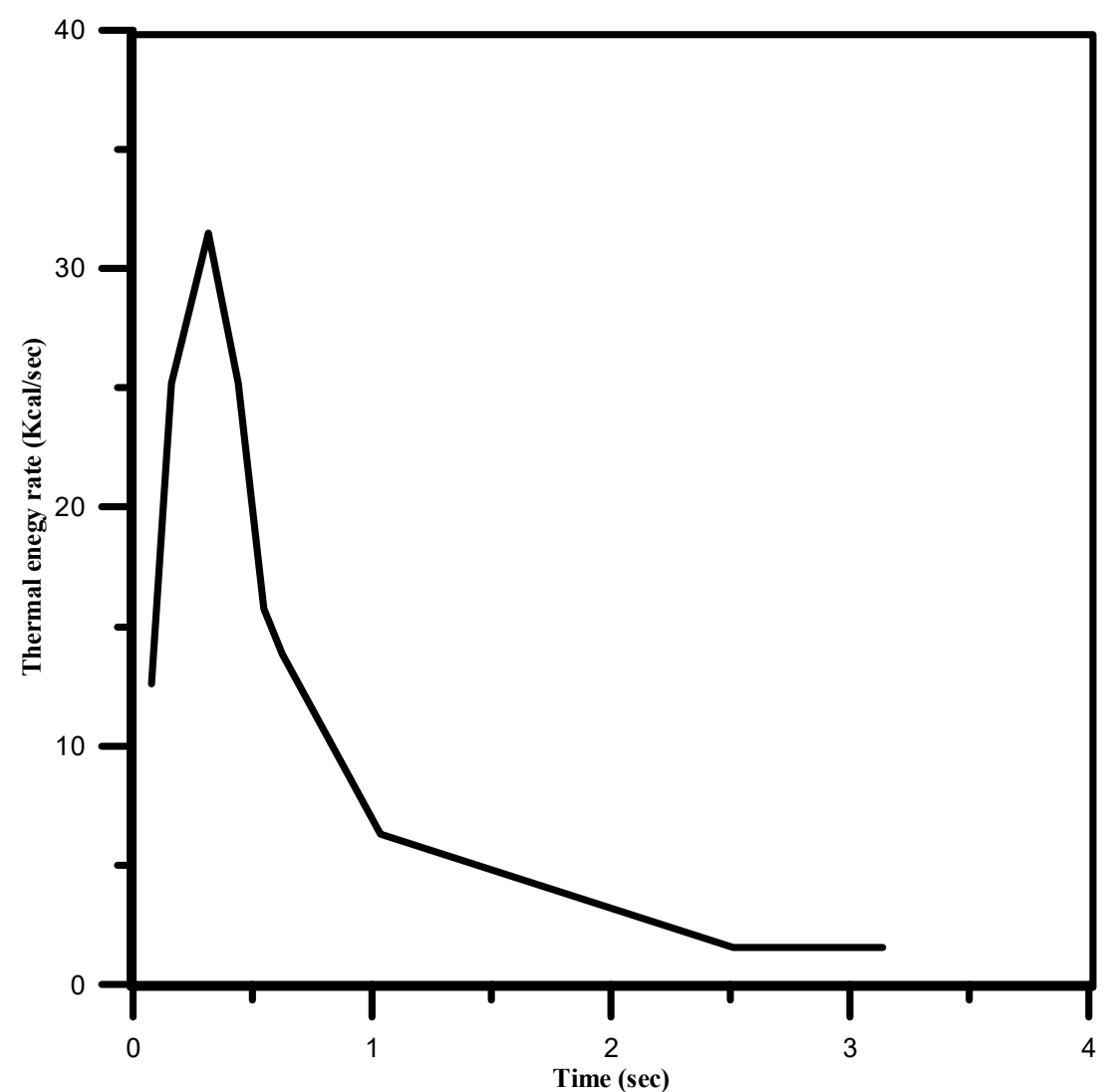

Figure 3. Thermal energy emission rate as a function of time for an explosion yield of 50- $70 \mathrm{KT}$

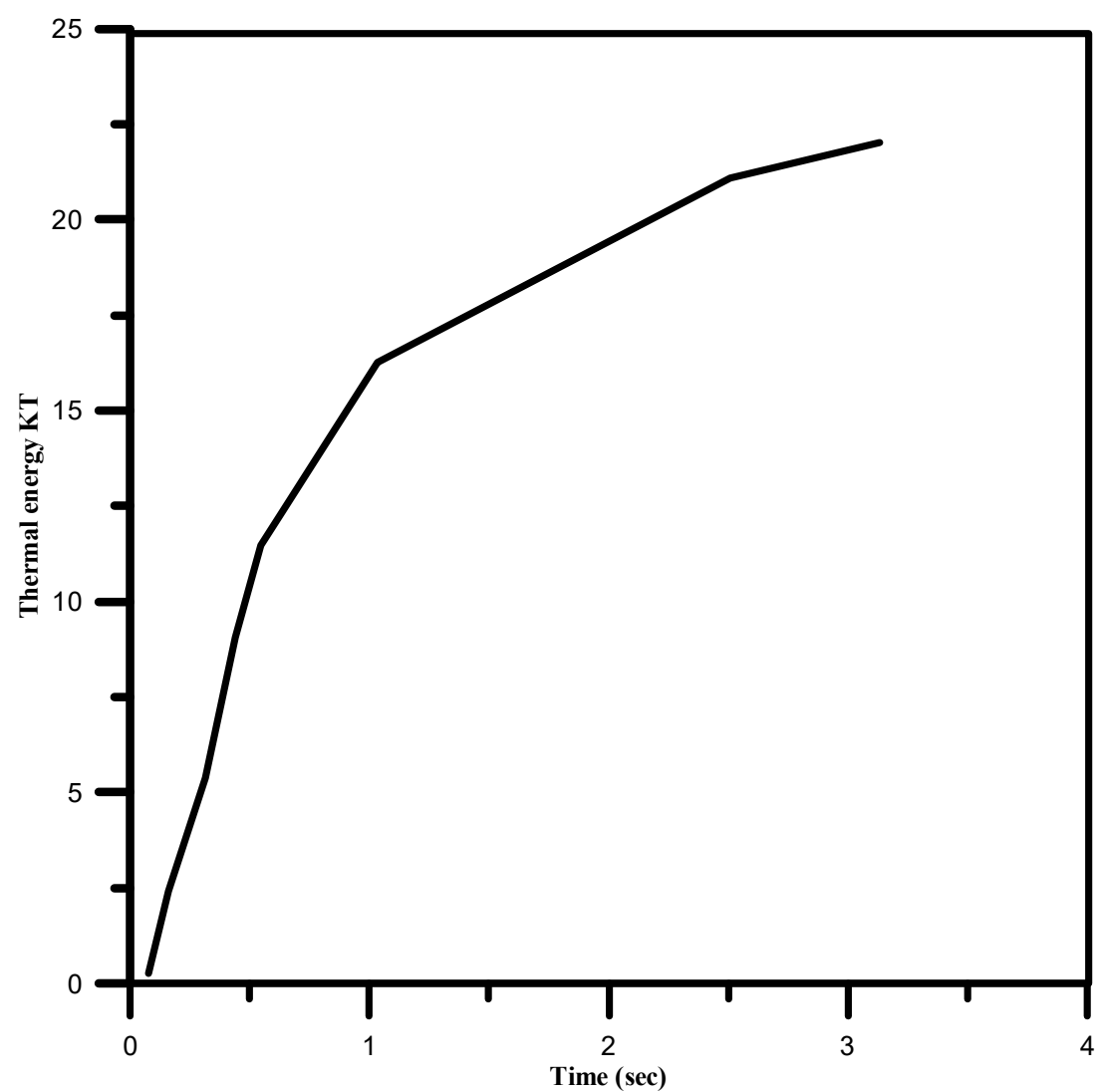

Figure 4. Thermal energy yield vs. time due to a 50- $70 \mathrm{KT}$ nuclear explosion 


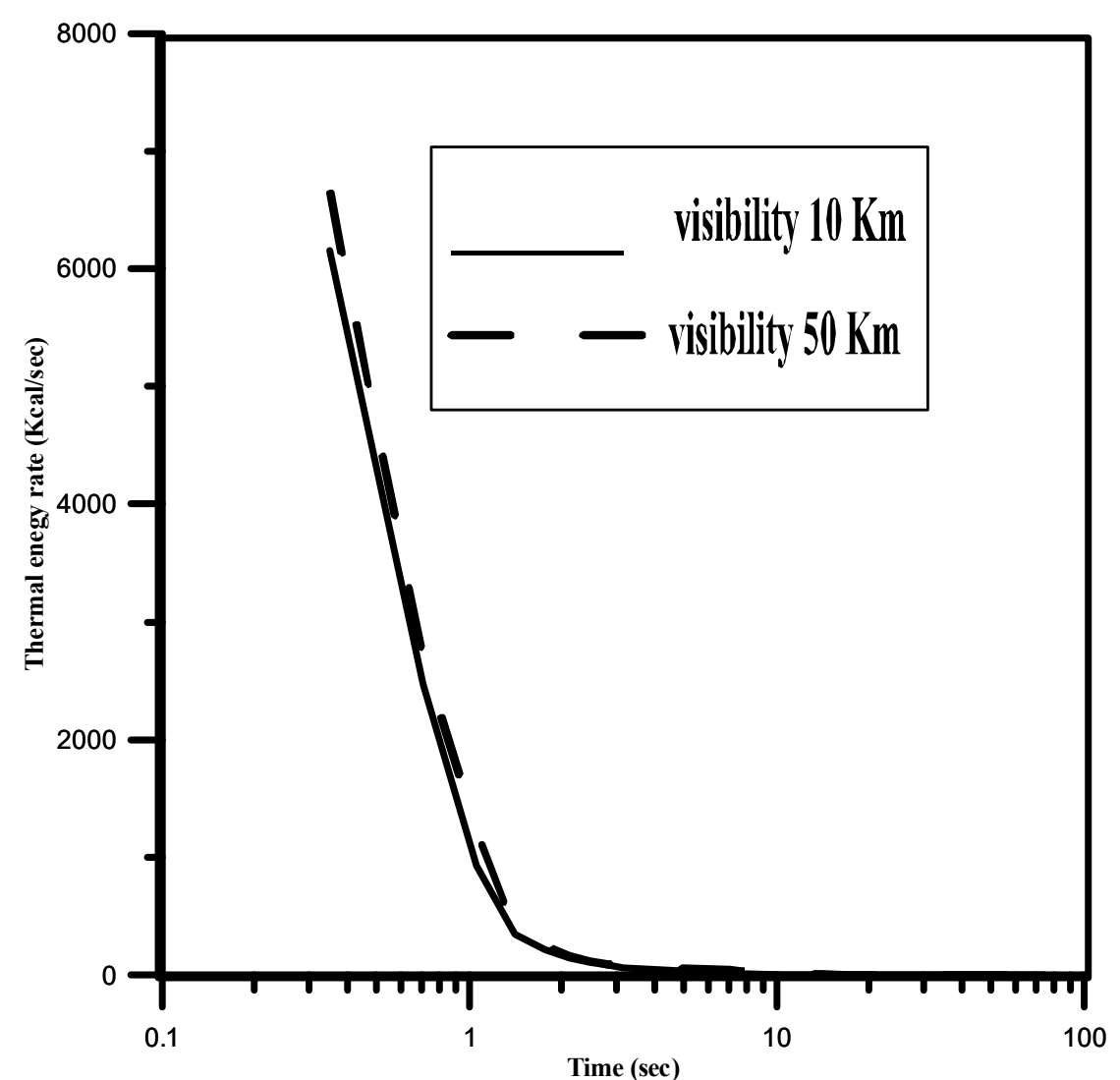

(a)

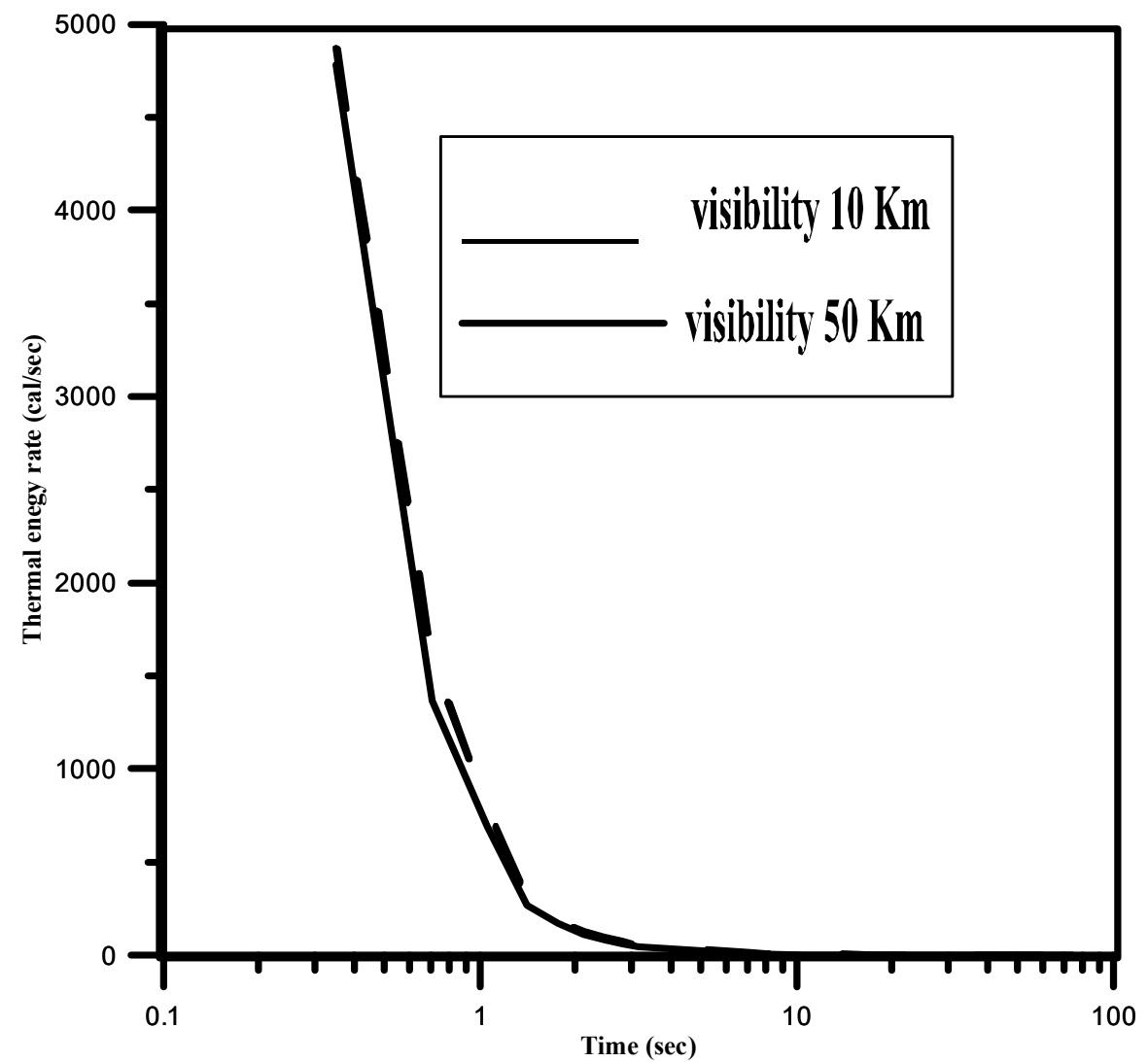

(b)

Figure 5. Thermal exposure as function of distance from explosion point for two visibility degrees: a. aerial explosion. b. surface explosion 


\section{Conclusions}

The majority of thermal emissions due to low yield nuclear explosions in the range 50-70 KT are released within a very short duration after the explosion; about 20-23 KT would be released in about three seconds, hence the whole thermal burden is concentrated in the point zero leading to the expected devastating consequences and casualties as about $4000-6000 \mathrm{cal} / \mathrm{cm}^{2}$ heating rate would shock the surrounding environment. Also, the comparison between surface and aerial explosions has shown that the thermal exposure resulted by the former is about $60 \%$ of that from the later of the same yield whether at or far from the point zero and that the visibility has no certain effect on that thermal exposure for both types of explosions.

\section{References}

American National Laboratories ANL-5800.

DeVolpi, A., Minkov, V. E., Simonenko, V. A., \& Stanford, G. S. (2004). Nuclear Shadowboxing: Contemporary Threats from Cold War Weaponry. Fidlar Doubleday.

Glasstone S., \& Seasonske A. (2012). Nuclear Reactor Engineering (4rd ed.). Springer Science \& Business Media.

Glasstone, S., \& Dolan, P., (1977). The Effect of Nuclear Weapons (3rd ed.), McGrawHills Co.

Kramm, G., \& Mölders, N. (2009). Planck's Blackbody Radiation Law: Presentation in Different Domains and Determination of the Related Dimensional Constant. Journal of the Calcutta Mathematical Society, 5.

Lamarsh, J. R., \& Baratta, A. J. (2017). Introduction to Nuclear Engineering. $4^{\text {th }}$. Revised edition, Pearson.

Robert, J. (2008). Johnston's Archive, Nuclear Weapons. Retrieved from http://www.johnstonsarchive.net/nuclear/

\section{Copyrights}

Copyright for this article is retained by the author(s), with first publication rights granted to the journal.

This is an open-access article distributed under the terms and conditions of the Creative Commons Attribution license (http://creativecommons.org/licenses/by/4.0/). 